\title{
Golden Section Proportionality IN THE MUSIC OF DZIHAN \& KAMIEN
}

\author{
$\because$ Feature Article $\longrightarrow$ \\ Dave Collins \\ INDEPENDENT RESEARCHER (UK) \\ MichaEL DUNN \\ University Centre, Doncaster College (UK)
}

\begin{abstract}
Academic studies of the golden section are evidenced across a range of disciplines. In music the discourse has been dominated by analytical studies from the realm of classical music but much less with relation to popular music. In order to explore this absence an in-depth case study was undertaken into the golden section within EDM through an analysis of the musical output of the European duo, dZihan \& Kamien. The authors employed time-based rather than conventional score-based analytical procedures, that is, through counting elapsed recorded musical time. Key musical event points relating to compositional structure provided criteria against which calculations were made, while the deviation of musical event points from the mathematically calculated golden section points was also evaluated. From some 66 tracks by dZihan \& Kamien analysed, 45 demonstrated less than just 3.5 percent deviation from calculated golden section points.
\end{abstract}

KEYWORDS: golden section, EDM, musical proportion, digital composition

DAVE COLLINS gained his PhD at the University of Sheffield (UK) in the psychology of musical composition alongside a career as an educator. He is the founding editor of two academic journals, the International Journal of Performance Arts and Digital Media and the Journal of Music, Technology and Education. His key publications are in the field of creative cognition exemplified in musical composition and the search for appropriate methods of enquiry. This led to his published book The Act of Musical Composition by Routledge in 2016. He now acts as consultant in the field of professional development in higher education. Email: davestorth1@gmail.com

Michael Dunn is Programme Leader for the BA Hons Creative Music Technology programme at University Campus Doncaster. Research interests are diverse and include publications upon the study of creative cognition and the use of computer systems, and the role of music technology in education. Alongside lecturing on the BA, Michael also works as a sound artist, software engineer, composer and performer, with an emphasis on collaborative practice. Recent work includes the Floating Memories AR sculpture installation in July 2021, and We Are Transient poetry soundscapes broadcast for the COP26 summit in November 2021. Email: m.p.dunn@live.com

Dancecult: Journal of Electronic Dance Music Culture 13(1): 101-128

ISSN 1947-5403 @2021 Dancecult http://dj.dancecult.net https://dx.doi.org/10.12801/1947-5403.2021.13.01.07

ddencecult 


\section{INTRODUCTION}

The history and influence of what is known as the golden section within human thinking and upon human creativity reaches back to Euclid in the fourth century BC and reappears in differing terminologies-golden section, golden ratio, golden mean, divine proportionthroughout Western thought since. Understood as a measure of proportionality and balance, the golden section, in purely geometric terms, occurs when a line or distance is divided in such a way that the ratio between the lesser $[\mathrm{B}]$ and greater $[\mathrm{A}]$ lengths is equivalent to the ratio of the greater length $[\mathrm{A}]$ to the whole $[\mathrm{C}]$, which can be expressed as $\mathrm{A}: \mathrm{B}=\mathrm{C}: \mathrm{A}$. Put numerically, if the whole is a single unit, then the value of the larger length is 0.618 and the lesser 0.382 . Expressed as a percentage the golden section of a distance or length occurs at a point corresponding to 61.8 percent of the whole.

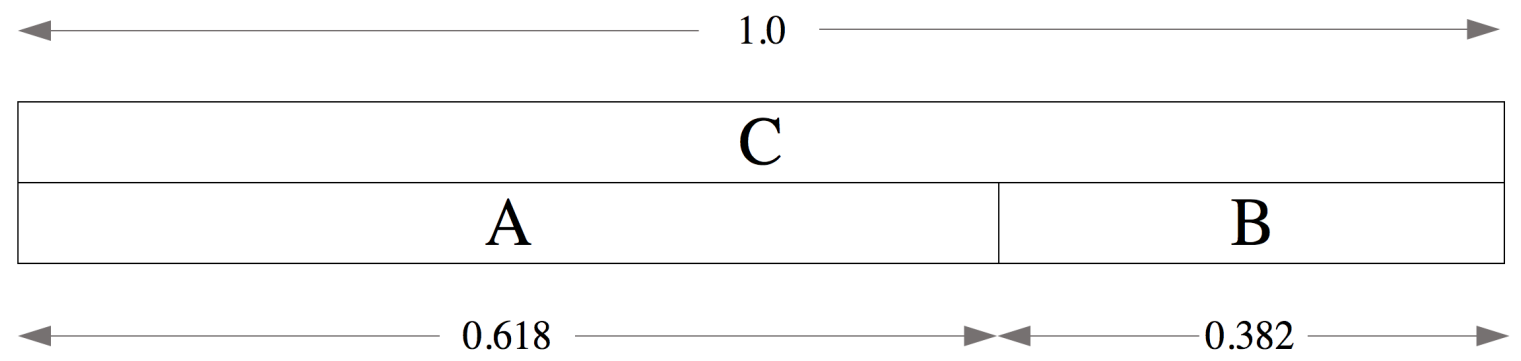

Figure 1. Geometry of the Golden SeCtion

This ratio or proportion based on irrational numbers has been conjectured as a mathematical principle not only reflecting universal laws like the structure of DNA, the growth patterns of plants, the shape of seashells and the spiral structures of galaxies. ${ }^{1}$ It is said to be also embedded in the products of human creativity such as architecture, graphic design, product design and so on. ${ }^{2}$ Alongside this extensive literature from within the visual arts, there also exists a body of scholarship regarding the golden section and its relationship to music, primarily with respect to notions of structural balance and proportion.

\section{The Golden Section and Music}

The relationship of the golden section to music dates back to the nineteenth century with Zeising's 1854 landmark book "New Theory of the Proportions of the Human Body" where he argued the case for establishing universal laws of beauty-encapsulated in the golden section-which would correspond to observable patterns in nature and art. ${ }^{3}$ However, the main growth of serious scholarship in the realm of music and the golden section began in the late twentieth century and as Michelle Phillips has pointed out, "from 1970 to the 
present day, the number of publications that mention the golden section has increased each decade" (Phillips 2019: 3), primarily exemplified in the work of scholars such as Ernest Lendvai and Roy Howat. ${ }^{4}$ To a lesser extent, the creative output of other composers in relation to the golden section has been explored by a diverse range of studies that include musical works spanning some seven hundred years. ${ }^{5}$

In very much the same way that golden section proportionality in the visual arts has been calculated through the counting of lengths or distance, the analytical procedures in these music-based studies have been implemented through the horizontal arithmetical counting of the notation of barlines, pulse and individual notes throughout the score of a particular piece.

\section{Determining Golden Section Event Points in Music}

The analytical procedures within the literature cited above employ a wide range of musical factors to determine what are called later in this study "golden section event points". In essence, event points occur when the musicologist uses particular musical parameters in a proportional analysis of a chosen piece of music; these may be dynamics, pitch, harmony, tempo, instrumentation and timbre, or a combination of more than one parameter. Some criteria used in studies have included changes of key, musical pauses, a return to the tonic key, the introduction of new themes and so on. What is clear is that a very diverse selection of music elements have been used by analysts across a range of classical music to enable their calculations of golden section (GS) event points, ranging from small scale musical pieces such as Howat's analysis of Debussy's five minute long Jardins sous la pluie for piano to larger scale works such as Lendvai's study of Bartók's three movement Sonata for Two Pianos and Percussion at around twenty six minutes (Howat 1993: 136-38; Lendvai 1996: 18-26).

\section{Proportional DeViation}

Of course, in any numerically based analysis of a piece of music some consideration needs to be paid to what degree of mathematical deviation from the golden section ratio can be regarded as meaningful. In this respect Adams makes the following important observation:

For the analyst who seeks any kind of credibility in claiming the use of GS in a work, it is crucial to minimize the extent of acceptable deviation from the exact GS ratio. After all, GS proportions are perilously close to one-third and two-thirds, fundamental divisions in music. Slightly overshooting the first or undershooting the second can easily bring the composer into the purview of GS" (Adams 2003: 243-44).

He goes on to suggest that a reasonable margin might be 2 percent. Atlas, in discussing the potentiality for contradictions of golden section points when the music is being performed, points out in his scrutiny of recordings of Puccini aria from La Boheme that these range from $1.6 \%$ to $2.66 \%$ (Atlas 2003: 277). Rofe, in his analysis of the golden section in the music of Shostakovitch, employs an accuracy margin of plus/minus 1.5 percent (Rofe 2008: 32). 


\section{The Golden Section and non-Classical Musics}

As can be seen, the studies outlined above have been concerned with the golden section in Western classical music spanning a time period of at least six centuries and a wide range of styles from early mediaeval choral music to opera and twentieth century electronic music. And within the broad spectrum of what constitutes classical music there have been a lesser number of studies in other genres such as musique concrète and electroacoustic music. ${ }^{6}$ There is a paucity of published papers on the golden section in the similarly wide stylistic field of popular music; thus this study seeks to explore possible golden section proportionality within popular instrumental music, specifically electronic dance music (EDM), doing this through the work of European duo dZihan \& Kamien. ${ }^{7}$

\section{THE MUSiC OF DZIHAN \& KAMIEN}

dZihan \& Kamien's music is broadly characterized by a blend of instrumental jazz and electronic idioms fused by layers of acoustic and synthetic parts, often with an emphasis on near-Eastern modes in the lead lines. In terms of genre, their work straddles downtempo, nu-jazz and acid jazz with prominent traits of house, funk and soul. Tracks are largely instrumental and range in duration from around two to eight minutes. Instrumentation typically comprises drums or percussion, bass and keys, over which a range of different instruments carry the lead lines, often using near-Eastern modes and instruments with free improvisation. There is also extensive use of sampling, editing and looping techniques throughout, indicating the use of contemporary digital audio workstation (DAW) software tools. This is further evidenced by each track having a consistent tempo, suggesting the use of a grid-based timeline to record and/or sequence the tracks. ${ }^{8}$ In terms of compositional form, their music largely aligns with contemporary electronica idioms. Percussion is in a simple quadruple meter at a regular tempo over which thematic material is introduced and repeated (looped) with some variation. And development is not established through change of key, tempo or introduction of contrasting movements, but through variation in the combination of different instrument parts. Typically, a predominant theme is established, followed by contrasting instrumental and/or breakdown sections, and finally a return to the original theme.

\section{Structure in the Music of DZiHan \& Kamien}

Whilst tracks from the third studio album, their 2009 Music Matters, are more poporiented, relatively short (mean duration 3'46") and utilize a typical verse-chorus song form to provide a sense of unity throughout the song, the most prevalent characteristics of dZihan \& Kamien's work can be found in the studio albums Freaks \& Icons (2000), Gran Riserva (2002) and Lost and Found (2010). These are more representative of EDM form, combining and varying loop-based layers of instrument parts to articulate the development of a single musical theme, with most tracks lasting between four and six minutes (mean duration 5'05"). Here, the main theme provides a sense of unity across the track, while 
significant changes to instrumentation and dynamics in the breakdowns provide the main source of musical, sonic and dynamic contrast.

\section{EDM FORM IN DZIHAN \& KAMIEN'S WORK}

At this point, it should be made clear that it is inaccurate to define dZihan \& Kamien's music wholly as EDM, since musical content and instrumentation identify more clearly with jazz, funk and middle eastern styles. Furthermore, the majority of their work has an emphasis on acoustic instruments played by real musicians as opposed to electronic sounds controlled by computer sequencers. However, their work is representative of the loop-based production paradigm allied to contemporary EDM that essentially manipulates one musical idea across a whole composition through different combinations of looped instrument parts.

Whilst it serves as a relatively primitive overview, not being representative of the nuanced and divergent nature of contemporary EDM, DJ Stanley's "song map" does provide a useful framework of reference for the analysis of how musical materials are structured through time, and it continues to appear in the literature to illustrate the rudiments of EDM form (Butler 2006: 222). ${ }^{9}$

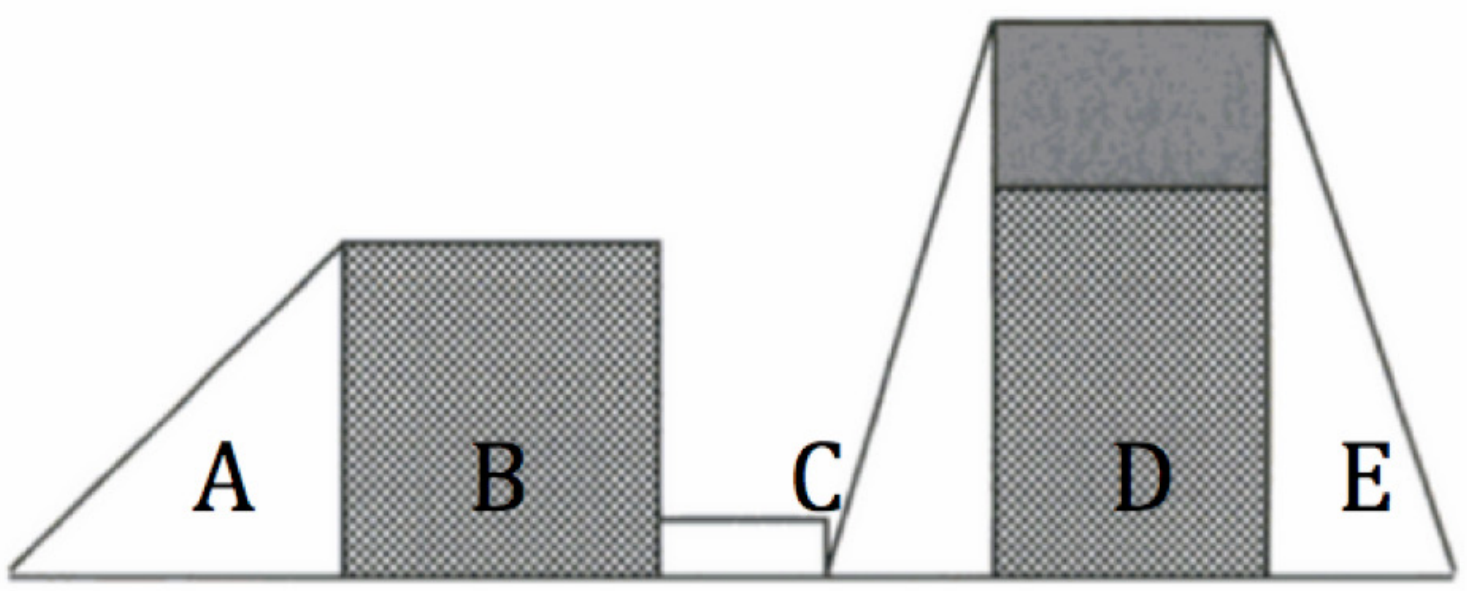

FIGURE 2. SONG MAP FOR EDM FORM

This model communicates not only the order of sections through time ( $\mathrm{x}$-axis), but also the emergent arc of dynamic intensity (y-axis). Thus, the width of any given region indicates its duration as a scaled proportion of the whole track, whilst vertical height represents an aggregated measure of the amplitude, instrumental complexity and overall energy presented by that section. The above literature is largely consistent in its identification of the different sections. 


\begin{tabular}{|l|l|l|}
\hline A & Lead-in / Intro & establishes feel, builds up to the core \\
\hline B & Core & main thematic material introduced \& developed \\
\hline C & Breakdown & majority of instruments muted, ambient feel, builds to drop \\
\hline D & 'Drop' \& Core & max intensity, to reintroduce main thematic material \\
\hline E & Lead-out / Outro & gradually drops away to finish the track \\
\hline
\end{tabular}

Figure 3. StRUCTURE OF EDM Form

The core can be thought of as the foremost section of the piece that carries the main theme at its highest intensity. It is described as the "fullest" section (Anderson \& Eigenfeldt 2011: 9). All instruments and loop layers are usually "thicker" and "simultaneously active" (LópezSerrano et al. 2016: 503). Meanwhile, underpinning bass and percussion provide the track's "regular groove" (Solberg 2014: 73). Looking at DJ Stanley's song map, it can be seen that the core sections (labelled B and D) establish the main material at the highest intensity around which the other sections are arranged.

The breakdown denotes a distinct section within the track that performs two important functions. Firstly, it contrasts with the preceding core section (B) which is often highly repetitive and thus susceptible to becoming stale. Secondly, it builds emotional tension and heightens musical anticipation towards the reintroduction of the core (D) at a key point referred to as the drop, and in doing so renders the final core section more powerful. Thus, it can be seen that the function of the breakdown is as "a contrasting section to the verse...to build tension, and lead back or crescendo to the verse in anticipation of 'the drop"' (Anderson and Eigenfeldt 2011:9).

The drop occurs when the breakdown ends and the final core section begins; to reference the earlier song map, this is the point at which $\mathrm{C}$ transitions to $\mathrm{D}$. This moment is interpreted as the "culmination of the track" (Solberg \& Jensenius 2017: 308). It is the "tensionresolving part" which Solberg describes as the highest intensity point of the composition (Solberg 2014: 68-70). This could be understood as the pivotal moment of the composition that elicits a "heightened and intensified emotional experience" in the listener through the careful construction of the preceding breakdown section (Solberg 2014: 74).

Within the context of this broad EDM structure, the authors had noted (informally in the first instance) some particular resonance with the golden section in the music of dZihan \& Kamien, which consequently provided the impetus to examine their music in more detail. Furthermore, given the substantial and varied musical output of the duo, with over 50 tracks incorporating elements of downtempo, trip-hop, house and other loopbased EDM sub-genres, the focus on dZihan \& Kamien's repertoire provided a breadth and diversity of examples. As a result a more in depth and detailed study of the whole of their output was undertaken. 
Initial observations seemed to show that the point of golden section in dZihan \& Kamien's tracks often coincided with the start or end of breakdown or instrumental sections, while more extensive listening also pointed towards middle-eight and bridge sections as being potentially prominent. Significantly, this shaped the overall approach towards determining golden section event points in the study; that is to say, it focussed the analysis upon the boundaries of these key sections that demarcated their start and end points, which are now referred to as sectional boundary points. Consequently, the function and importance of these sections within their respective compositional wholes was considered, which necessitated an interpretation of each track's overall structure and how it was organized through the ordering of sub-sections across the timeline.

What unified these sectional boundary points in terms of function was that they marked the junctures at which significant musical changes occurred. For example, the end of an instrumental section might transition into the start of a breakdown, or the breakdown back to the core. Furthermore, these boundary points often expressed the composers' decision to introduce contrast through new musical layers and significant changes to instrumentation and dynamics. In the case of the breakdown and instrumental sections, quite often their end points actually represented what could be considered the pinnacle of the piece, where dynamic intensity built towards the drop and a final reprise of the core. The significance of the sections themselves was also intimated by their uniqueness and prominence, since the breakdown and instrumental sections often only occurred once in the track and were emphasized by extended duration, variation in instrumentation, significant dynamic changes and sonic manipulation. Collectively, these criteria reinforced an approach towards determining sectional boundary points as meaningful golden section event points, and as a result, the analysis was predicated on the significance of these sections within the overall compositional structure.

\section{MATERIALS AND METHOdS}

Accessing dZihan \& Kamien's catalogue of work was a relatively straightforward process. Using Discogs as a database of all official releases, it was possible to source physical CDs and to access individual tracks using online streaming services (Spotify and YouTube). To arrive at a definitive list of recordings for use in this study, it was firstly necessary to filter out duplicated releases, radio edits of longer tracks and remixes by other artists. This left 67 tracks. By taking a proportional sample from this list, a comprehensive exploration of the prevalence of the golden section within their music then became feasible.

The challenge of course would be to implement the predominant methodology of counting from a musical score, which has formed the backbone of all previous golden section studies in musical composition. However, since dZihan \& Kamien's mode of music creation is through DAW-based software tools, any analysis cannot be contingent upon counting from a musical score. Similarly, since the tempi in all the analysed tracks remain consistent, issues of performance variation impacting upon score-based analysis are irrelevant. Score- 
based counting was jettisoned and replaced with a temporally-oriented (elapsed, or linear time) methodology of counting fixed musical recordings of tracks in minutes and seconds.

This time-based analytical procedure was then used to calculate the golden section point for each track, where the total duration of a track was independently measured, converted into seconds and multiplied by the golden section constant $(0.618) .{ }^{10}$ So, for example, the mathematically derived golden section point-hereafter referred to as the calculated GS point-for Ocean Air (2000, duration 5'20" or 320 seconds) was calculated to occur at 3'18" (198 seconds) as follows: GS point $=320$ secs ${ }^{*} 0.618=198$ secs $=3^{\prime} 18^{\prime \prime}$.

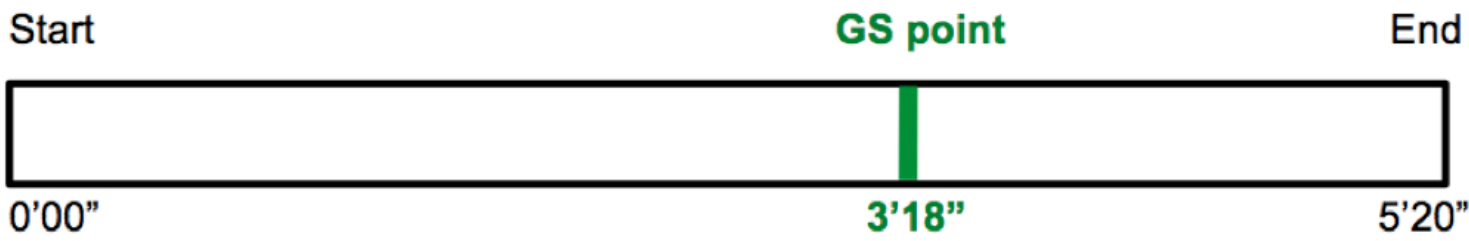

Figure 4. Deriving the mathematically calculated golden section (GS) point. The calculated

Following the GS point calculation, a structural analysis was undertaken for each piece by listening through in real-time from beginning to end, taking note of the order, duration and organisation of the different musical sections, the instrumental arrangement and any prevalent dynamic changes. In essence, the aim was to establish an overview of each composition's structure, to enable informed judgments to be made about the calculated GS point in the context of the whole composition. An example of this structural overview is shown below, using Ocean Air (2000) to illustrate.

Start
\begin{tabular}{|c|c|c|c|c|c|c|}
\hline $\begin{array}{c}\text { Intro } \\
\text { A }\end{array}$ & $\begin{array}{c}\text { Main Theme } \\
\text { B }\end{array}$ & $\begin{array}{c}\text { Breakdown } \\
\text { C }\end{array}$ & $\begin{array}{c}\text { Main Theme } \\
\text { B }\end{array}$ & $\begin{array}{c}\text { Breakdown } \\
\text { C }\end{array}$ & $\begin{array}{c}\text { Main Theme } \\
\text { D }\end{array}$ & $\begin{array}{c}\text { Outro } \\
\text { E }\end{array}$ \\
\hline $0^{\prime} 00^{\prime \prime}$
\end{tabular}

Figure 5. OCEAn Air (2000) DUR. 5'20" simplified structural overview

The calculated GS point was then reviewed to ascertain whether any significant musical events coincided with its intersection. In the example above, it can be seen that the calculated GS seems to occur close to the sectional boundary point between the main theme and the breakdown, and so this would be noted and scrutinized further. 


\section{TEMPoral DeVIation}

When determining whether a track supported any coincidence between the calculated GS point and an identified musical event point, any such musical events are unlikely to occur at the exact timing of the calculated GS, and, reflecting the literature's reference to acceptable deviation, a figure of $+/-3.5$ percent was implemented in order to determine whether any such musical event was indeed close enough to be permissible. This also took into account Adams' concerns that GS proportions are "perilously close" to the common divisions in musical structure of one-third/two-thirds (Adams 1996: 243). The acceptable deviation - which will now be referred to as the Deviation percentage-was calculated as follows: Deviation $=($ GS point - Musical Event $) /$ Total Track Duration.

To illustrate this in Ocean Air, the GS point of 3'18" (198 seconds) is just two seconds away from the start of the breakdown at 3'20" (200 seconds). Dividing this time difference by the track's total duration of 5'20" (320 seconds) results in a deviation percentage of -0.625 percent. Since this figure is within the threshold of $+/-3.5$ percent this was considered as close enough to the GS point to be deemed coincident. Had the deviation percentage been beyond the value of $+/-3.5$ percent it would have been rejected. ${ }^{11}$

\section{RESULTS}

Applying this methodology across all 67 of dZihan \& Kamien's tracks, 22 were excluded from further analysis for the following reasons: one was inaccessible (Sammy Fu vinylonly release); seven had no significant musical event points at the calculated GS point and fourteen had musical event points with greater than a 3.5 percent deviation. The remaining forty-five tracks were found to support coincidence of the calculated GS point with key musical event points, within the threshold of 3.5 percent deviation. The most significant initial observation was that the calculated GS point of a large proportion of tracks appeared to coincide with the start or end of key musical passages, most commonly the breakdown but also instrumental and bridge sections. Beyond this, there were other occurrences where the calculated GS point coincided with more unique musical event points such as the holistic division of a track into separate proportions. ${ }^{12}$ The inverse GS point was also considered, leading to further instances of coincidence against key musical event points. ${ }^{13}$ Consequently, it was possible to establish three clear event categories that brought all these examples together in a structured overview of how and where the calculated GS points coincided with musical event points for dZihan $\&$ Kamien's tracks. 


\begin{tabular}{|l|l|l|}
\hline Event Type 1 & Marks start of key musical section* & $\mathrm{n}=21$ \\
\hline Event Type 2 & Marks end of key musical section* & $\mathrm{n}=12$ \\
\hline \multirow{2}{*}{ Event Type 3 } & Marks other significant musical section & $\mathrm{n}=2$ \\
\cline { 2 - 3 } & Coincidence based on 0.382 (inverse) GS point & $\mathrm{n}=7$ \\
\cline { 2 - 3 } & Marks start of ramp event & $\mathrm{n}=3$ \\
\hline
\end{tabular}

* key musical section $=$ breakdown, instrumental or bridge

Figure 6. Golden Section eVent type categories

To clarify, an overview of the whole data collection process is presented in the diagram below.

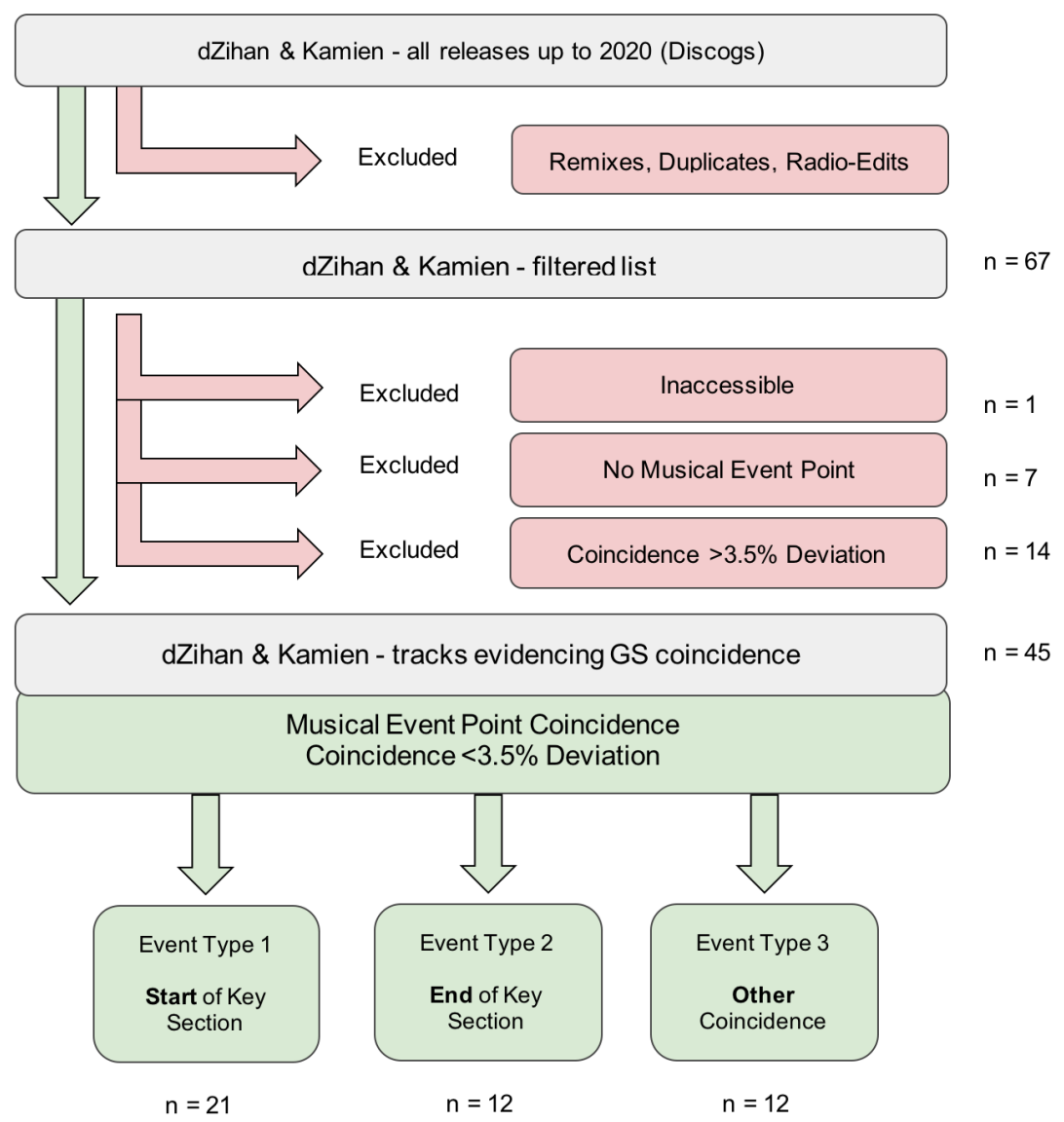

Figure 7. OVERVIEW of DATA COLLECTION PROCESS 


\section{An Analysis of DZihan \& Kamien's Music through the Event Types}

\section{EVENT TYPe ONE (TWENTY-ONE TRACKS)}

This event group brought together all instances where the calculated GS point coincided with the start of a key section within the composition. Of the 21 tracks included, ten coincided with the start of the main breakdown, four coincided with the start of a break, four coincided with the start of an instrumental and three coincided with the start of a bridge.

\begin{tabular}{|c|c|c|c|c|c|}
\hline \multicolumn{6}{|c|}{ Event type one: start of key section } \\
\hline Track & Duration & $\begin{array}{l}\text { Calculated GS } \\
\text { Point Time }\end{array}$ & Musical Event Point Type & $\begin{array}{l}\text { Musical Event } \\
\text { Point Start Time }\end{array}$ & Deviation \% \\
\hline Weltempfanger & $04: 24$ & $02: 43$ & Breakdown Start & $02: 44$ & $+0.38 \%$ \\
\hline Ocean Air & $05: 20$ & 03:18 & Breakdown Start & $03: 20$ & $+0.63 \%$ \\
\hline Unknwn & $04: 46$ & $02: 57$ & Breakdown Start & $02: 55$ & $-0.70 \%$ \\
\hline Arabesq & $05: 14$ & $03: 14$ & Breakdown Start & $03: 17$ & $+0.96 \%$ \\
\hline I Guess She.. & $04: 13$ & $02: 36$ & Breakdown Start & $02: 39$ & $+1.12 \%$ \\
\hline Mojamore & $04: 04$ & $02: 31$ & Breakdown Start & $02: 34$ & $+1.23 \%$ \\
\hline Homebase & $07: 12$ & $04: 27$ & Breakdown Start & $04: 33$ & $+1.39 \%$ \\
\hline Noon & 06:05 & $03: 46$ & Breakdown Start & $03: 39$ & $-1.92 \%$ \\
\hline Thrill & $04: 43$ & $02: 55$ & Breakdown Start & $02: 46$ & $-3.18 \%$ \\
\hline Satellite Tank & $06: 51$ & $04: 14$ & Breakdown Start & $04: 27$ & $+3.17 \%$ \\
\hline Just You \& I & $05: 52$ & $03: 38$ & Break Start & $03: 40$ & $+0.57 \%$ \\
\hline Gutenm'duft & $04: 34$ & $02: 49$ & Break Start & $02: 54$ & $+1.82 \%$ \\
\hline 1 & $02: 17$ & $01: 25$ & Break Start & $01: 28$ & $+2.19 \%$ \\
\hline 99 & 03:10 & $01: 57$ & Break Start & $01: 52$ & $-2.63 \%$ \\
\hline Dundaeova & $04: 19$ & $02: 40$ & Instrumental Start & $02: 41$ & $+0.39 \%$ \\
\hline Call Me & $04: 51$ & 03:00 & Instrumental Start & 03:03 & $+1.03 \%$ \\
\hline Ahmet Bont & $05: 31$ & $03: 25$ & Instrumental Start & $03: 32$ & $+2.11 \%$ \\
\hline Join Us & $3: 49$ & $2: 22$ & Instrumental Start & $2: 15$ & $-3.1 \%$ \\
\hline Summer Fever & $04: 14$ & $02: 37$ & Bridge Start & $02: 38$ & $-0.39 \%$ \\
\hline Busted & $03: 43$ & $02: 18$ & Bridge Start & $02: 16$ & $-0.90 \%$ \\
\hline Life Can Be Good & $03: 40$ & $02: 16$ & Bridge Start & $02: 14$ & $+0.91 \%$ \\
\hline
\end{tabular}

Figure 8. EVEnt type one dATASET 
The start of the breakdown was by far the most common musical event to coincide with the calculated GS point in this event category, accounting for ten of the twenty-one tracks. Whilst each track's breakdown varied in terms of duration, common to all these instances was the section's role within each track, clearly demonstrating the defining features identified in the previous discussion of the breakdown and EDM form (introduction of contrasting material, reduction in dynamic intensity, removal of key percussive elements such as kick drum and lead towards the drop and a reprise of the core).

For example, in I Guess She... (2000) thematic material is introduced and developed through the intro up to 1'29", after which the fullest combination of instrumental layers, representing the core, plays until 2'04'. The track drops in intensity through an instrumental section to lead into the breakdown at 2'39', which in this example starts three seconds after the GS point (deviation of 1.12 percent). The majority of the instrument parts, including the primary percussive layers, are removed during the first half of the breakdown, leaving just the vocal sample "I guess she fell in love" playing over sustained electric piano, muted kick and hi-hat; this is a unique combination of instrument layers in the context of the whole composition. Use of reverb and delay create a sense of ambience and space that complements the significant drop in dynamic intensity. The second half of the breakdown introduces percussive layers to build intensity towards the drop where the core is reintroduced at 3'10" and continues into the outro and the end of the track.

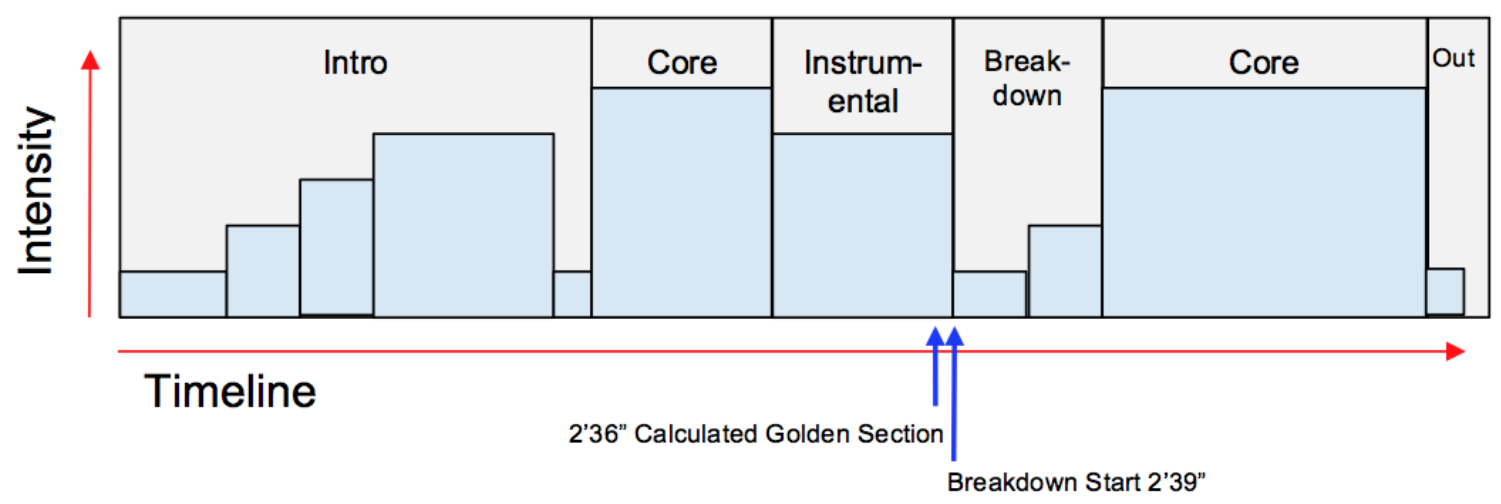

Figure 9. I GUess SHE... (2000) DUR. 4'13"

The other nine tracks in which the golden section coincided with the start of the breakdown bore similar characteristics; the calculated GS point marked the transition from a prior, busier and more intense section-most often the core-to a more ambient or sparse section with muted percussion and attenuated dynamic intensity.

Four further examples-Just You and I (2000), Gutenmorgenduft (2002), I (2010) and 99 (2020) - also evidenced coincidence at the start of breakdowns. However, there were some differences in the defining features of these sections. For example, they were of significantly shorter duration, or they existed in relation to another more prominent breakdown section 
elsewhere in the track that led us to differentiate these instead as break sections, in order to remain true to the defining features of the breakdown in EDM form. ${ }^{14}$ Nevertheless, they did appear to serve a similar purpose, in that the calculated GS point would coincide with the start of a break section in which instruments would thin out, percussion would be removed and intensity would diminish, before returning to the core.

The other examples in this event group indicated close coincidence of the calculated GS point with the start of an instrumental-Dundaeova (2002), Call Me (2010), Ahmet Bont (2010) and Join Us (2010) - or bridge section-Summer Fever (2005), Busted (2005), Life Can Be Good (2005). These could be considered as musical event points since they evidenced the composers' intention to introduce contrasting musical materials at a clear sectional boundary point.

\section{EVEnt TyPe TWo (TWELVE TRACKS)}

The second event group brought together all instances where the calculated GS point coincided with the end of a key section within the composition. Of the twelve tracks included, six coincided with the end of the main breakdown, two coincided with the end of a break and four coincided with the end of an instrumental.

\begin{tabular}{|c|c|c|c|c|c|}
\hline \multicolumn{6}{|c|}{ Event type two: end of key section } \\
\hline Track & Duration & $\begin{array}{l}\text { Calculated GS } \\
\text { Point Time }\end{array}$ & Musical Event Point Type & $\begin{array}{l}\text { Musical Event } \\
\text { Point Start Time }\end{array}$ & $\begin{array}{l}\text { Deviation } \\
\%\end{array}$ \\
\hline 2 MInutes & $05: 26$ & $03: 21$ & Breakdown End & $03: 21$ & $+0.00 \%$ \\
\hline EPA & $04: 52$ & 03:00 & Breakdown End & 03:04 & $+1.37 \%$ \\
\hline Waltz & $04: 10$ & $02: 34$ & Breakdown End & $02: 38$ & $+1.60 \%$ \\
\hline Airport & $05: 12$ & 03:13 & Breakdown End & $03: 18$ & $+1.60 \%$ \\
\hline Carta de Conducao & $04: 33$ & $02: 49$ & Breakdown End & $02: 56$ & $+2.56 \%$ \\
\hline Nargileh & $04: 58$ & 03:04 & Breakdown End & $03: 12$ & $+2.68 \%$ \\
\hline Slowhand Hussein & $05: 24$ & 03:20 & Break End & $03: 24$ & $+1.23 \%$ \\
\hline After & $07: 23$ & $04: 34$ & Break End & $04: 23$ & $-2.48 \%$ \\
\hline Around & $03: 41$ & $02: 17$ & Instrumental End & $02: 16$ & $-0.45 \%$ \\
\hline Basmati & $05: 27$ & $03: 22$ & Instrumental End & 03:15 & $-2.14 \%$ \\
\hline Debussy & $04: 27$ & $02: 45$ & Instrumental End & $02: 38$ & $-2.62 \%$ \\
\hline Barbeque & $02: 33$ & 01:35 & Instrumental End & 01:30 & $-3.27 \%$ \\
\hline
\end{tabular}


Coincidence of the calculated GS point with the end of the main breakdown section was most prevalent, accounting for six of the twelve tracks, with the remaining instances marking other breaks and instrumental sections. While in the first event group the calculated GS point marked the beginning of the breakdown, the examples in this second event group occurred at the end of the breakdown, which would typically then transition into the final core section. It is argued that this is particularly significant, since the construction of EDM form indicates that the second half of the breakdown tends to ramp up towards the drop and the return of the core, representing the culmination or "highest intensity point" in the track (Solberg 2014: 70). To clarify using DJ Stanley's EDM song map, this would correspond with the transition from section $\mathrm{C}$ to $\mathrm{D}$.

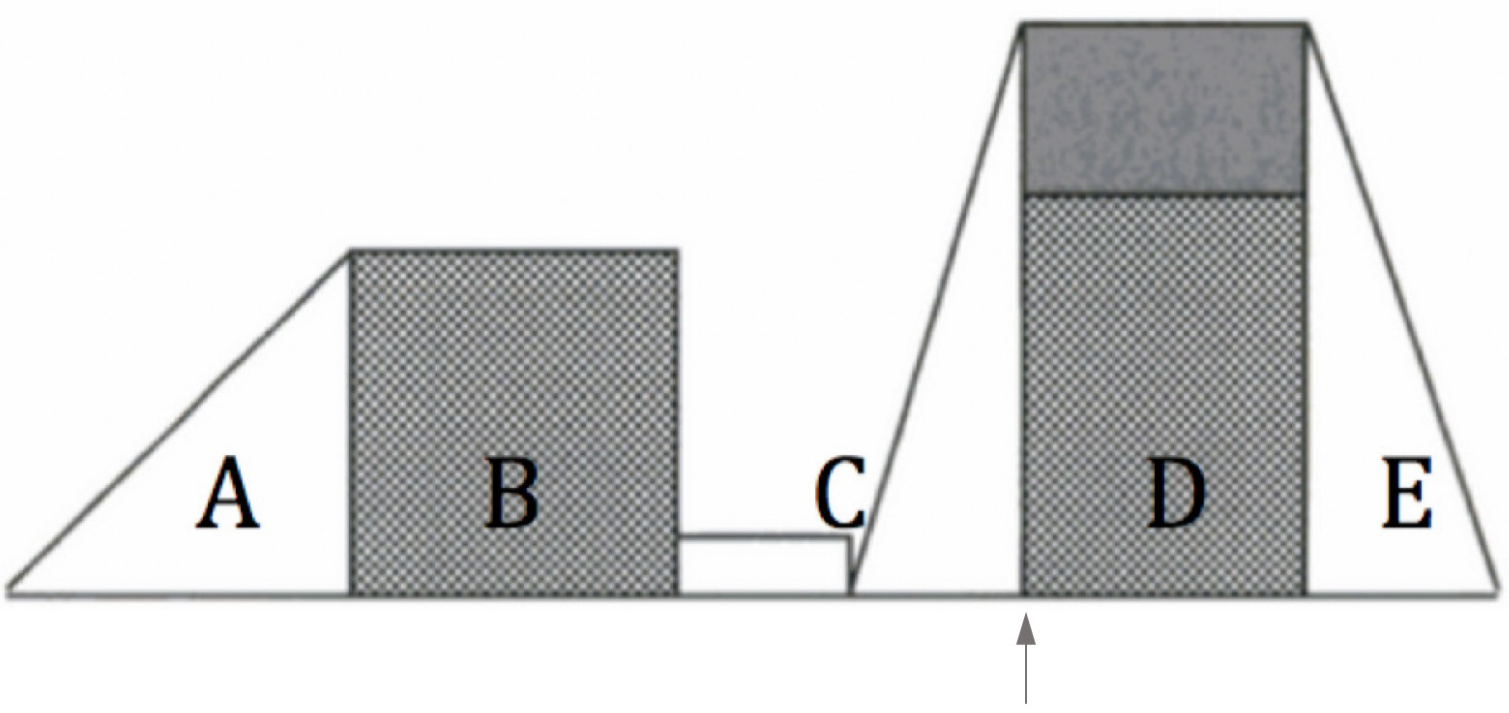

End of Breakdown

Figure 11. EVENT TYPE TWO MAPPED AGAINST EDM SONG MAP

In this sense, the Event Type Two breakdown examples evidence the calculated GS point coinciding with what could be argued as the pinnacle of the entire composition: the drop. Using Airport (2002) to illustrate, after a lead-in that introduces some of the melodic and rhythmic elements, the core is established and supported by full percussion. Subsequent to this, the track moves to a slightly less intense instrumental section which sees some layers, such as the prominent synth, removed, while other new instrumental parts are introduced to offer variation and contrast. 


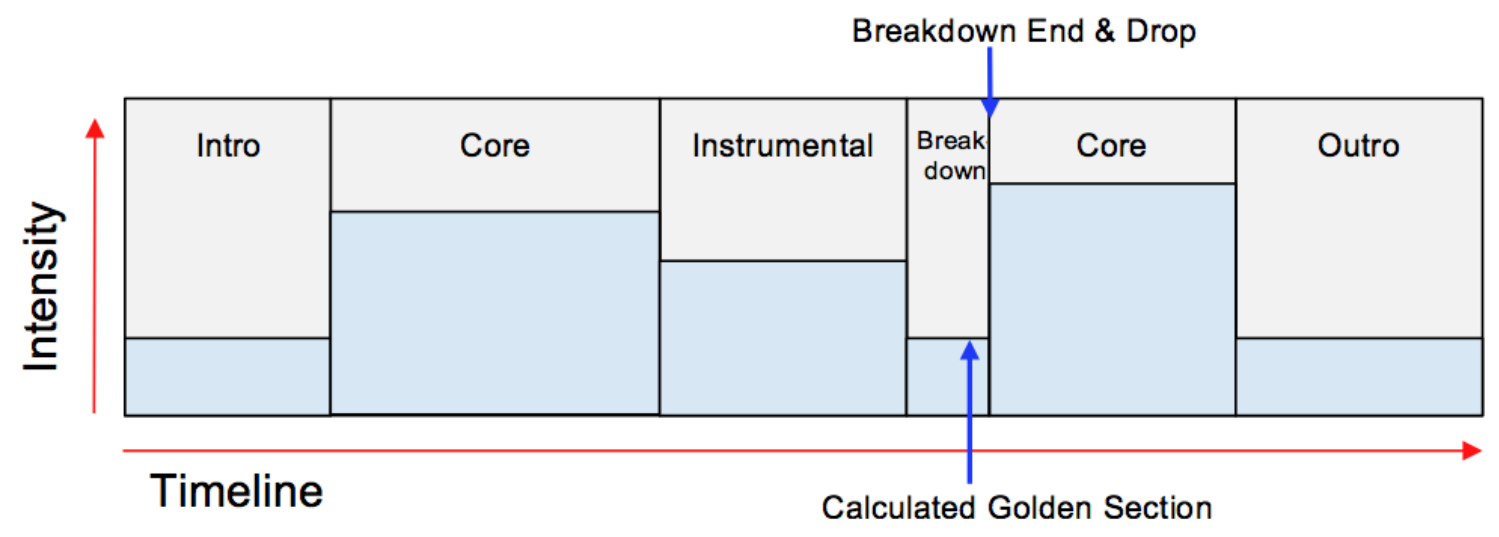

FIGURE 12. AIRPORT (2002) DUR. 5'12"

At the breakdown, the majority of the percussion drops away to leave just the main chord progression and melody playing against a minimal backdrop. The calculated GS point occurs three seconds (deviation 1.34 percent) before the end of the breakdown and the drop, at which point the core is re-established at its maximum intensity, supported by full percussion and other key instrument layers. Some unique parts are introduced after the drop, for example a trumpet line, which renders the final core section more prominent in the context of the whole composition. Finally, the track drops down to the outro and the end of the piece.

In addition to the six tracks with breakdown end events, two others-Slowhand Hussein (2000) and After (2000) —evidenced coincidence with less significant break sections which were either preceded and followed, respectively, by longer and more prominent breakdown events. As already explained, it was considered appropriate to distinguish between breakdown and break events.

Finally, there were four further instances where the calculated GS point coincided with the end of instrumental sections which also tended to then lead into the core at the end of the track: Around (2010), Basmati (2002), Debussy (2010) and Barbeque (2010). Interestingly, parallels can be drawn between these instrumental sections and the breakdown sections, since both seem to perform the unique and essential function of preparing the listener for a re-introduction of the core at the drop, as a final reprise of the track's main thematic material.

Regardless of the exact nature of each of these examples, they are united by the fact that the end of a clearly defined, discrete musical section, integral in establishing contrast within each piece, coincides closely with the calculated GS point. In many of these examples, this point of coincidence also represents the pinnacle of the composition. For more often than not, the end of the breakdown or instrumental marks the drop and/or a final reprise of the core at maximum dynamic intensity and extended duration. 


\section{EVENT TyPe Three (TWELVE TRACKS)}

The final event group brought together any remaining instances of golden section proportions aligned with clear musical events and sectional boundary points. This included examples where, in the absence of any coincidence at the 0.618 calculated GS point measured from the start of the track, the 0.618 calculated GS point was instead measured from the end of the track, or what has been termed here the inverse calculated GS point. Also included are instances in which the calculated GS point marked holistic structural proportions between verse/chorus groupings and ramp events, all of which are explained in more detail below. Out of the twelve tracks identified, seven marked key sections or structural proportions at the inverse calculated GS point, two marked other structural proportions in the compositions and three marked the start of a ramp event that built towards the drop.

\section{Event type three: other musical event points}

\begin{tabular}{|c|c|c|c|c|c|}
\hline Track & Duration & $\begin{array}{l}\text { Calculated GS } \\
\text { Point Time }\end{array}$ & Musical Event Point Type & $\begin{array}{l}\text { Musical Event } \\
\text { Point Start } \\
\text { Time }\end{array}$ & Deviation \% \\
\hline Deep Disco & $05: 42$ & 02:11 (inverse GS) & Instrumental Start & $02: 12$ & $+0.29 \%$ \\
\hline I Wish & $04: 39$ & 01:47 (inverse GS) & Structural Proportion & $01: 48$ & $+0.36 \%$ \\
\hline Mad Man & $05: 06$ & 01:57 (inverse GS) & Breakdown Start & $01: 52$ & $-1.63 \%$ \\
\hline Terrorist & $05: 10$ & 01:58 (inverse GS) & Break / Instrumental Start & $02: 04$ & $+1.94 \%$ \\
\hline Drophere & $04: 27$ & 1:42 (inverse GS) & Verse End, Chorus Start & $01: 48$ & $+2.25 \%$ \\
\hline Colores & $03: 27$ & 01:19 (inverse GS) & Break Start & $01: 24$ & $+2.42 \%$ \\
\hline My Music & $03: 20$ & 01:16 (inverse GS) & Structural Proportion & $01: 23$ & $+3.5 \%$ \\
\hline Take a Minute & $03: 31$ & $02: 10$ & Structural Proportion & $02: 08$ & $-0.95 \%$ \\
\hline Waiting & $03: 27$ & $02: 08$ & Structural Proportion & 02:01 & $-3.38 \%$ \\
\hline Stiff Jazz & $05: 50$ & $03: 36$ & Ramp Start & $03: 37$ & $+0.29 \%$ \\
\hline Spacewater & $05: 18$ & $03: 17$ & Ramp Start & $03: 16$ & $-0.31 \%$ \\
\hline Where Are We? & $05: 36$ & $03: 28$ & Ramp Start & 03:32 & $+1.19 \%$ \\
\hline
\end{tabular}

Figure 13. EVEnT TYPE THREe DATASET

In order to calculate the inverse golden section point, the same methodology was applied as was outlined earlier (taking a track's total duration and multiplying it by 0.618 ). However, instead of then measuring this calculated duration from the start of the composition, the 
temporal measurement was taken from the end of the composition, which simply meant working with the same golden section proportions but in reverse order. What was found were further examples of coincidence with key sectional boundary points, including the start or end of breakdown and instrumental sections. For example, in Deep Disco (2010) after a short ambient introduction, the core is established with some slight variation in instrument layers until 2'12". Here, just one second after the inverse calculated GS point at 2'11", there is a pronounced change in direction as the track moves to an extended instrumental section that markedly contrasts the previous material. Subsequent to this, a short drum break at 3'52" signals a return to the core, which is then repeated al fine.

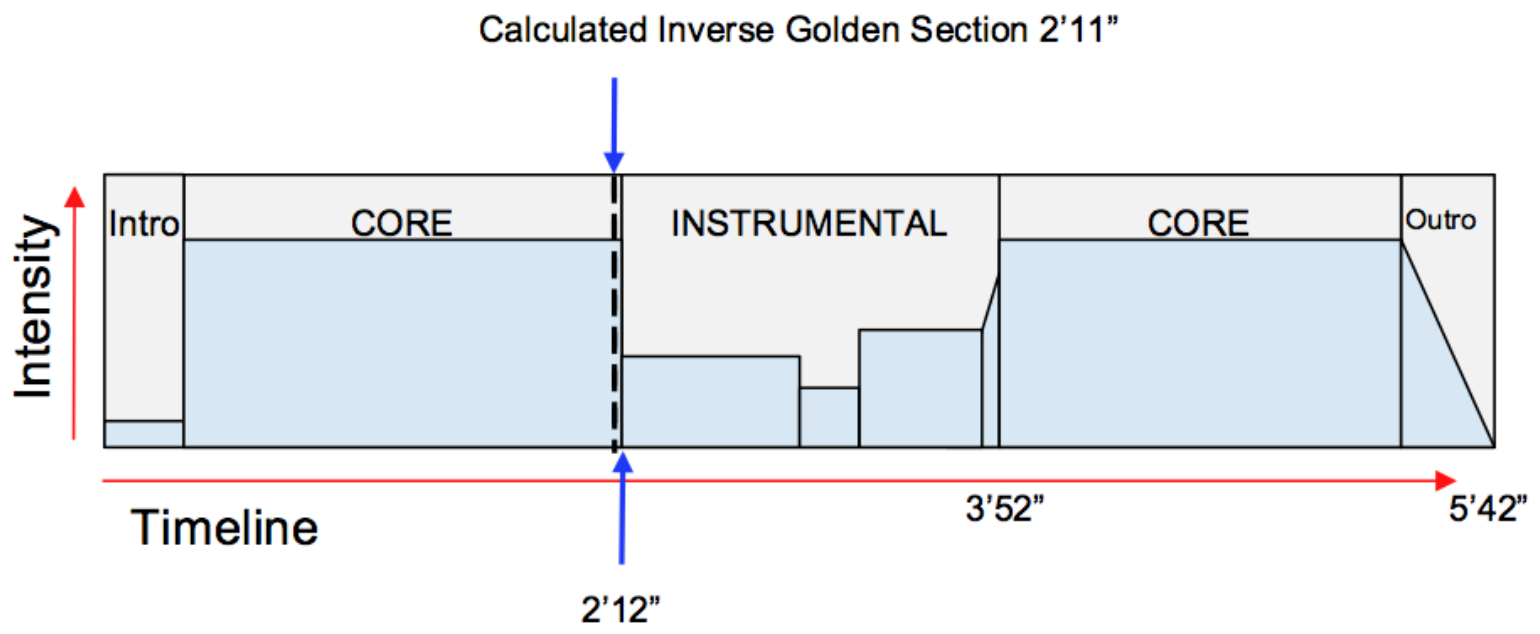

Figure 14. DeEP Disco (2010) DUR. 5'42"

Here, one can clearly see a very close correlation (deviation +0.29 percent) between the inverse calculated GS point (2'11") and the start of the contrasting middle section (2'12"). Essentially, Deep Disco, along with a number of other tracks in this group, demonstrates similar attributes of GS coincidence to those discussed in the first two event groups, the only difference here being that coincidence is mapped against the inverse mathematical GS proportion.

Other instances of the inverse calculated GS point present compelling support of golden section alignment that becomes apparent when examining the structural proportions of the composition as a whole. For example, in $I$ Wish (2005), the initial intro, verse, bridge and chorus are demarcated from the subsequent verse, triple chorus and outro by a short eight second section that slows to a brief pause. This is a unique moment in the track which seems to punctuate the whole composition by dividing it into two parts, $\mathrm{A}$ and $\mathrm{B}$ : 


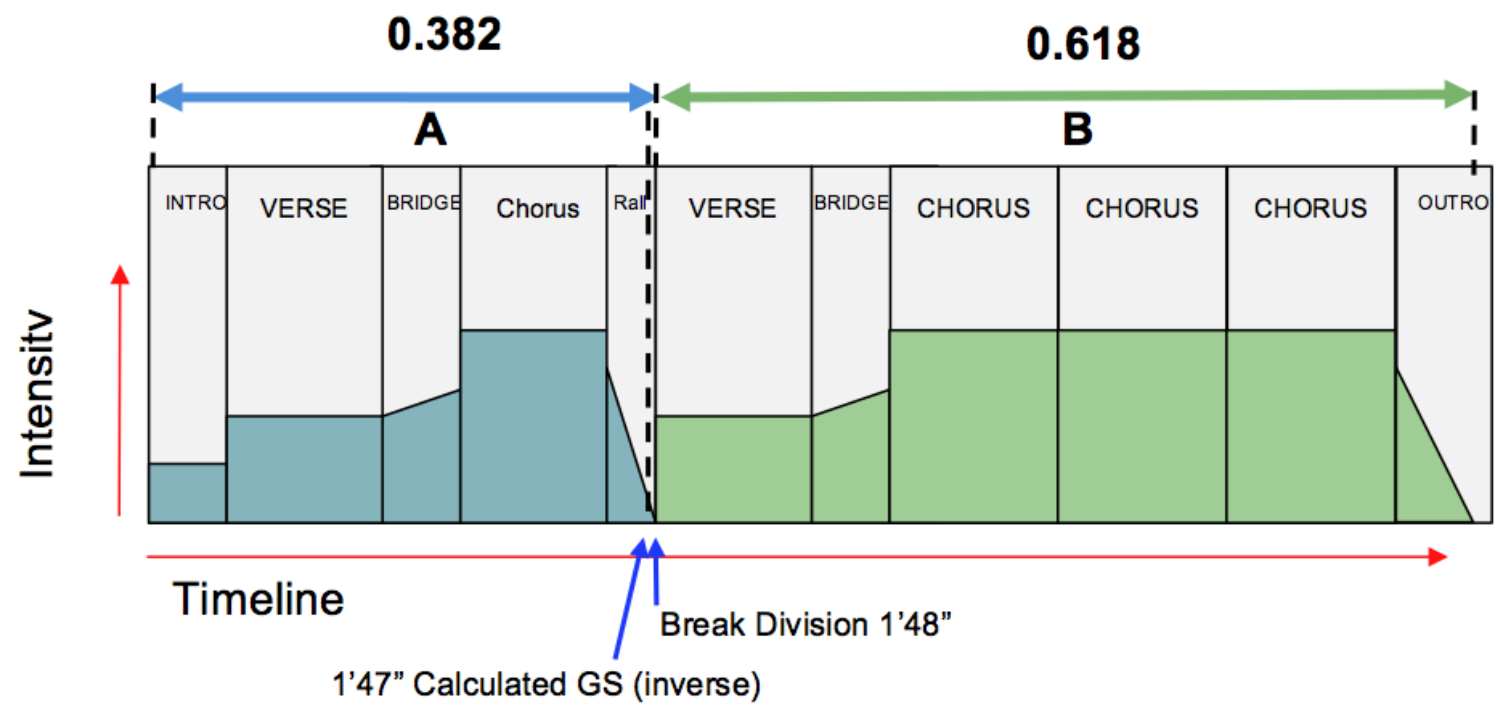

FIGURE 15. I WISH (2005) DUR. 4'39"

The ratio between former (A) and latter (B) parts portrays almost exact GS proportions of 0.382:0.618, with the inverse calculated GS point occurring at 1'47", just one second before the start of the new verse at 1'48" (0.36 percent deviation).

Similar proportionality can be found in the standard calculated GS point examples in this group, such as Waiting (2009), which can be subdivided into two. Part A consists of two verses and a chorus linked by a short bridge section. And part B is almost identical but only contains one verse. The calculated GS point occurs just after the end of the chorus in part A, at which point the track slows noticeably and attenuates in amplitude, adding an extra bar ( $t w o$ to three seconds) to the end of the chorus. This concludes part $A$ and enables a transition to part $\mathrm{B}$. Once again, this is a unique moment in the composition, and the perception is one of the music slowing to a momentary pause before the new verse is introduced.

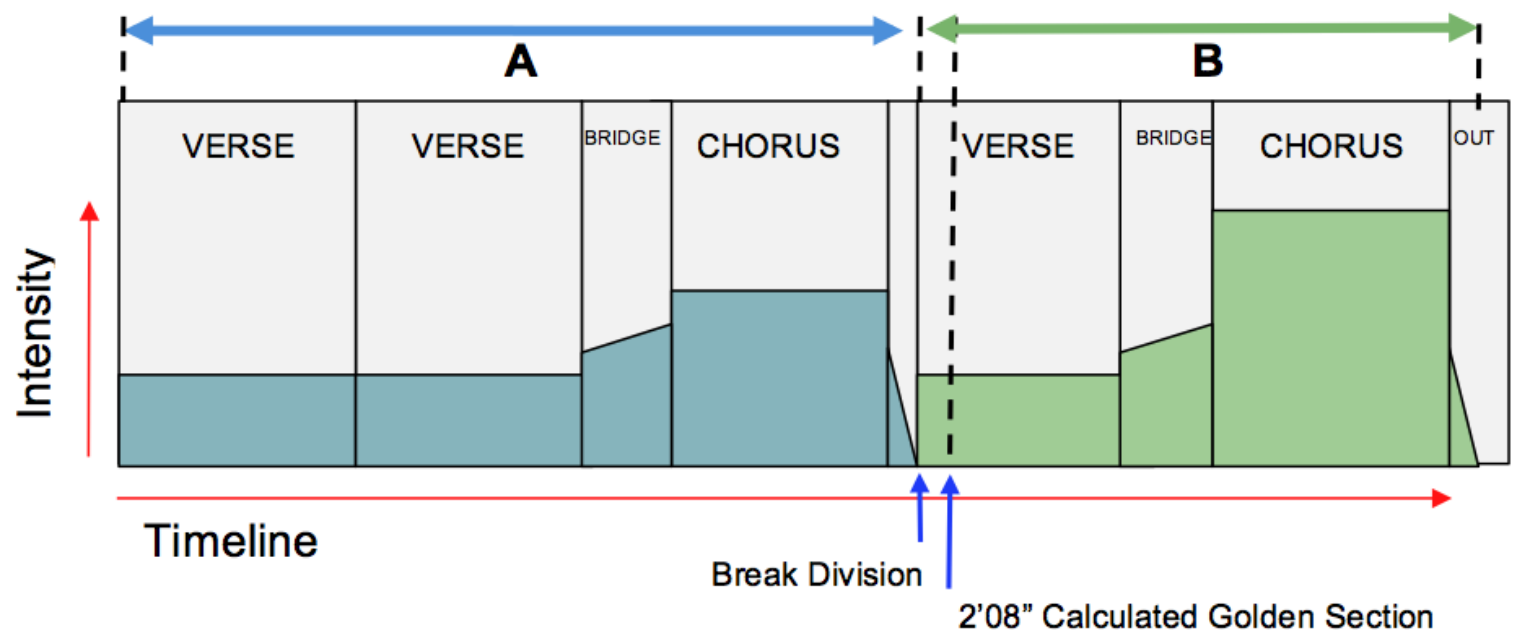

FIGURE 16. WAITING (2009) DUR. 3'27" 
Here, the calculated GS point could be interpreted to mark the division of the composition into former (A) and latter (B) parts which resemble golden section proportions, albeit approaching the limits of acceptable deviation at 3.38 percent. In a similar manner to $I$ Wish (2005), this example is indicative of a more holistic representation of the calculated GS since it can be seen how the entire composition $(\mathrm{A}: \mathrm{B}$, or $\mathrm{A}+\mathrm{B}: \mathrm{A})$ corresponds with golden section proportions (0.618:0.382 and 1:0.618 respectively).

Finally in this group, three instances were identified in which the calculated GS point marked the onset of musical and dynamic changes within the breakdown that indicated a build or ramp towards the drop: Stiff Jazz (2002), Spacewater (2000) and Where Are We? (2000).

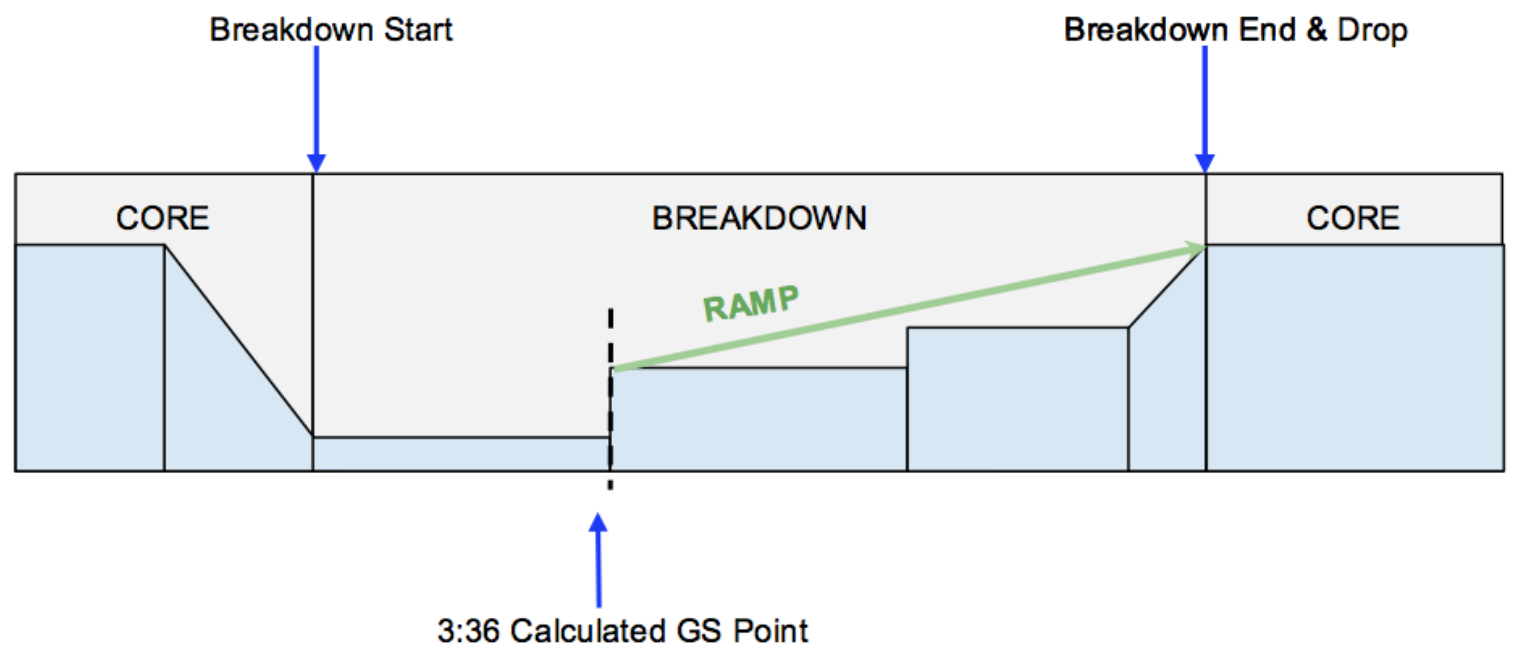

FigURE 17. STIFF JAZZ (2002) DUR. 5'50"

In these cases, each track transitions from core to breakdown and in doing so moves from a higher to lower intensity. Fewer instrument layers result in an ambient, open feel. Looking at Stiff Jazz (2002) as an example, the breakdown starts to build at 3'37', just one second after the calculated GS point (deviation 0.29 percent). The onset of the ramp is marked by the introduction of new instrument layers which provide a change of direction and a renewed sense of momentum, and the section continues to build in intensity as the drop approaches and all instrument parts are re-introduced for the core at 4' 15 ". To reiterate an earlier point, given the significance of the drop as the pinnacle of the whole track and the moment at which the final reprise of the core occurs at maximum dynamic intensity, these ramp events seemed particularly noteworthy. 


\section{SUMMARY}

From the sixty-six tracks subject to analysis, forty-five tracks supported alignment of the calculated GS point with significant musical events to within 3.5 percent deviation. This corresponds to a striking 68 percent of dZihan \& Kamien's tracks-just under five and a half hours of music-which evidence golden section proportions.

Of these tracks, deviation ranged from 0.0 to 3.5 percent with a mean average of just 1.58 percent, signifying a close alignment between the mathematically calculated GS point and the occurrence of key musical events. As a reminder, this deviation figure is an indicator of how closely the calculated GS points occurred in relation to the coincident musical event points, and thus a smaller deviation percentage value denotes a closer representation of golden section proportions within the music. These figures are broken down further in the schematic below, enabling comparison between the different Event type groups and against the overall aggregated figures.

\begin{tabular}{|l|l|l|l|l|l|}
\hline Group & Lower Range & Median & Mean & Upper Range \\
\hline \multicolumn{7}{|l|}{} \\
\hline Event Type 1 & 0.38 & 1.12 & 1.46 & 3.18 \\
\hline Event Type 2 & 0.00 & 1.87 & 1.83 & 3.27 \\
\hline Event Type 3 & 0.29 & 1.41 & 1.54 & 3.50 \\
\hline & & & \\
\hline All Groups 1-3 & 0.00 & 1.39 & 1.58 & 3.50 \\
\hline
\end{tabular}

Figure 18. DeViation PERCENTAGE OVERVIEW

Visualising this data graphically enables a better appreciation of its significance; the box plot below presents the average median and mean deviation amounts with the minimum and maximum deviation values at the lower and upper range boundaries and the interquartile range. This represents the midspread or central grouping of deviation values: 


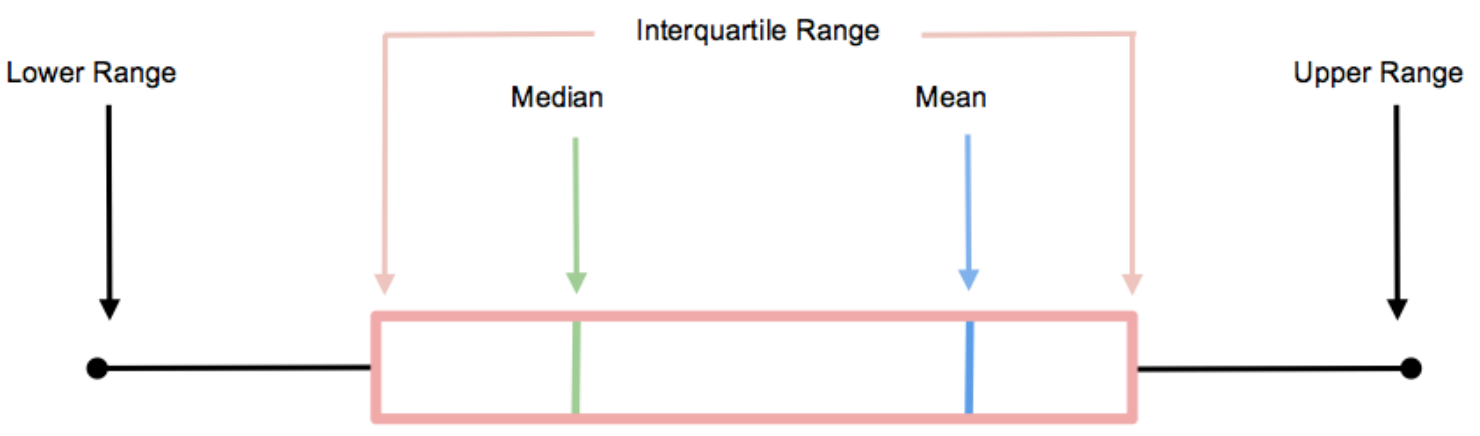

FigURE 19. BOX PLOT KEY

Thus, the box plot for each Event group illustrates the deviation measurements for all tracks included within that group. Each deviation measurement represents the time difference between the calculated GS point and the musical event point identified for each track. The further one moves to the left side of the graph, the lower the deviation, indicating a closer coincidence between calculated GS point and musical event point.

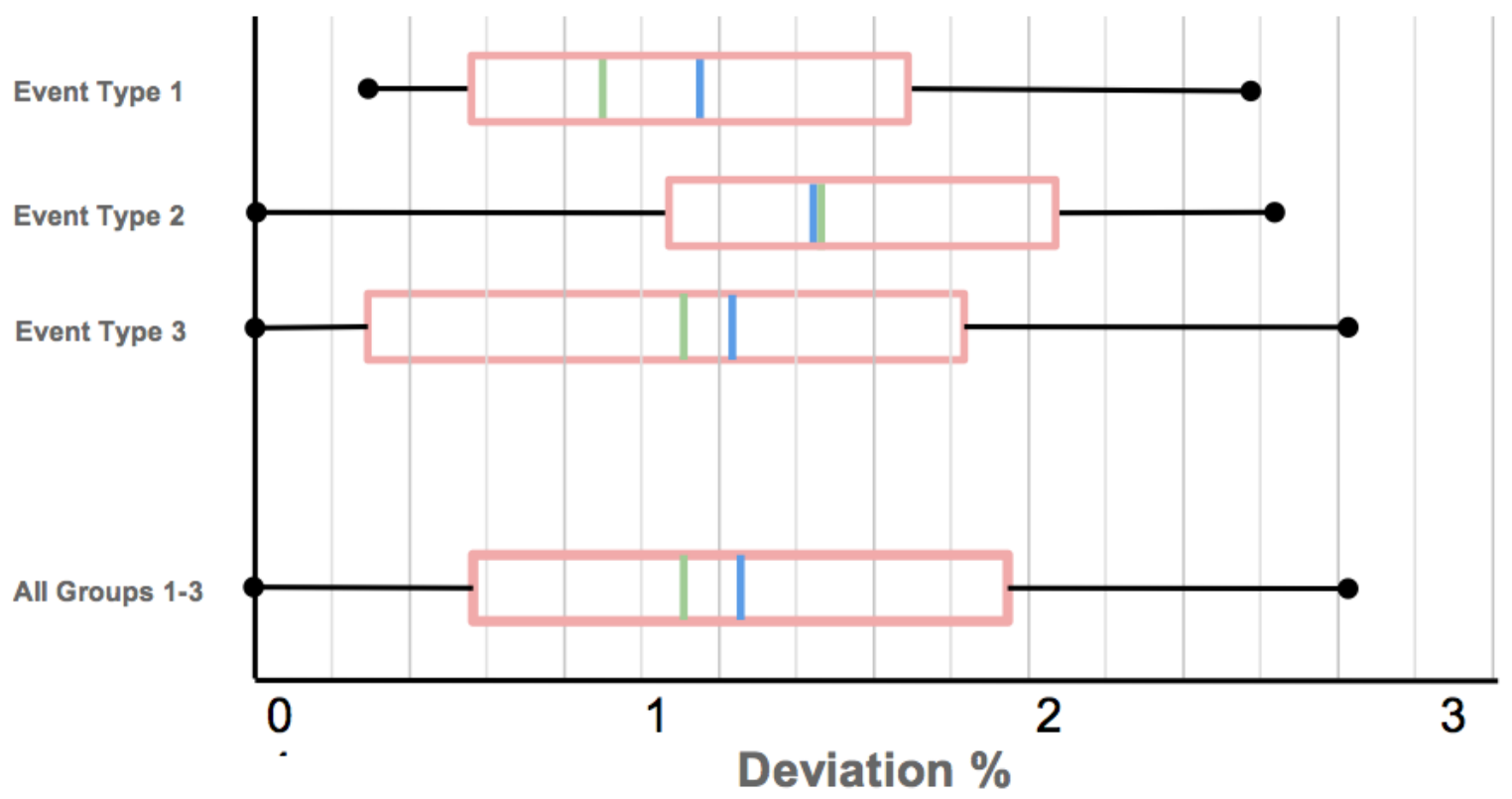

Figure 20. Deviation percentage overview box plots

Although originally setting a deviation threshold of 3.5 percent, the data actually indicate that the majority of tracks were well below this limit, as evidenced by the interquartile range for All Groups spanning from 0.7 percent to 2.42 percent. Therefore, the majority of the data would remain credible even within more stringent margins, such as the 2 percent "reasonable margin" described by Adams (1996: 244). 


\section{DISCUSSION}

The journey which began with an early intuitive hunch that one or two tracks from the creative output of dZihan \& Kamien might perhaps reflect golden section proportionality led to an in-depth analysis of over sixty of their songs. Experimental findings indicate that some sixty-eight percent of their tracks align to, on average, just under 1.6 percent overall deviation of the identified key structural events from the mathematically calculated golden section.

Acquiring this data meant implementing a different methodological procedure from any previously described in the literature. EDM-based music is not predicated on a musical score, but upon the use of DAW technologies. So it made sense to abandon score-based counting approaches, which have dominated golden section music analyses, and replace them by counting elapsed time. As pointed out earlier in this paper, there have been some not insignificant concerns by respected analysts themselves around the reliability of the counting bars methodology, in the main due to the inconsistent tempi across analysed works. However, in this study, the overwhelming majority of pieces under scrutiny employ a stable, consistent tempo. Additionally, there are no comparable issues regarding variations in performance interpretation from the composer's intended tempi, since each track/song exists as a finished recorded artefact. In effect, the creative acts of musical composition and production are one and the same. Counting in minutes and seconds not only releases the methodology from these issues but focusses the demarcation of key musical event points away from discerning them on a printed page to an aural apprehension of how such event points manifest themselves in experienced time.

As stated earlier, the bulk of studies on the golden section in the arts sit in the visual domain, and in this context the perception of proportional relationships is both holistic and simultaneous. For example, the proportional relationships lying within the various dimensions of a mediaeval cathedral, or the interrelationships between various components within a painting, can be apprehended in one moment. In the case of music this is not possible since it is time-contingent. Reybrouk suggests that, "since music is a temporal art [it] is characterized by the consumption of time. In distinction to, for example, a geometric figure which is perceived at a glance, it relies on the successive presentation of its component parts" (Reybrouk 2005: 12). And as Ray Howat points out, "if a painting or building is clumsily proportioned, a sensitive observer can see the fact in an instant; in music, though, we have to hear the piece through to make the equivalent evaluation" (1983: 1). In other words, when listening to music it could well be that the golden section is perceived retrospectively, after the event. ${ }^{15}$ Allan Atlas semi-humorously notes that this perception is "a far more complicated affair than that of spatial proportions, which are nice enough to stand still" (2003: 282). And as Boykan has rather acerbically pointed out, "you can easily compare lengths in the visual world, but it is rather a stretch to ask us to keep track of a ratio in a situation of gradual unfolding" (2004: 25-6). 
These are however, issues that relate more to the psychology of musical perception, which sits outside the scope of the current paper. When looking at how proportionality might function within the actual creative act of composition rather than its later perception, the matters of holistic visualisation described above may, particularly in the setting of digital compositional tools, be relevant. Macchiusi describes such a setting: "the DAW's particular visualisation of a composition as a compound graphical object, temporally delineated and stretched across a timeline, highlights a modular form of arrangement that centers a spatial analysis of music" (2017: 9). This spatial aspect, he continues, "is emblazoned across the screens of countless (music) producers, making up an integral part of their process" (Macchiusi 2017: 122). And within the spectrum of visual environments in a DAW, it is the so-called "arrange window" which allows the musician to comprehend what Macchiusi describes as the "synoptic outline" of the entire composition. ${ }^{16}$ This leads to the possibility that in such a creative digital workspace, the composer/arranger may be influenced-consciously or otherwise- by the visual representation of the emerging composition. Macchiusi goes on to state that, "Creating visual clarity forces many producers to constantly think analytically, visually defining the form and function of various sections of their arrangement while still in the midst of the compositional process" (2017: 142; our emphasis).

In email correspondence with dZihan \& Kamien this sense of synoptic visualisation was echoed when Vlado Dzihan said that, "as a composer/producer you develop more of a bird's-eye when you work on a piece, and that gives you a better overview regarding the flow between energy, pauses, dynamics, silence." ${ }^{17}$ This "birds-eye overview" might be used by any composer engaged in the creative act of composing, but it may well be reinforced even further by contemporary composers through their use of screen-based tools such as the DAW. The authors of this paper suggest that these digital tools might naturally engage a visual, holistic appreciation of possible golden section proportions upon the computer screen which might then in turn be translated into temporal music and sound events. This has been echoed by Marrington in his study of DAW-based musical composition.

...the entire composition can appear as a single entity on the screen. This presents an interesting deconstruction of the established notion of the composition as a design made apparent through unfolding in time and further emphasizes the composition as object in visual space (Marrington 2010:5).

Exploring this possibility inevitably then leads to the consideration of matters of compositional intentionality. In some of the literature, issues of conscious intention are discussed: to what extent is the musician aware of the golden section and how consciously do they incorporate such proportionality into their work ${ }^{18}$ From our written communication with Vlado Dzihan it was very clear that he had no deliberate intention to incorporate the golden section into his music. 
Vlado Dzihan: I'm familiar with these [the golden section and proportionality in music] although I do not have a specific knowledge about it.... I also believe that a formula or intention to use these principles on purpose to make music would turn out rather uninspiring. ${ }^{19}$

And when asked how the duo establish an effective balance between sections when structuring their music, Dzihan says it is "rather an instinct than a formula". Structuring a piece of music for him is...

Dzihan: ...similar to speech-you also do not talk in one stream, you take a breath, you make a pause, you might look for a right expression, you get louder or softer, etc. So it is the same with music - for instance, the tension, the focus might be given by the pauses and the silence.

Clearly, the act of composition described here is heavily reliant upon creative intuition and feel rather than the intentional use of any formal compositional procedures over and above any general alignment with EDM generic structures. If not intentional, the question then arises as to why some sixty-eight percent of the creative output of dZihan \& Kamien, sustained over a period of twenty years, reflects golden section proportionality to such a close degree?

\section{CONCLUSION}

From the findings outlined, the authors of this paper are led to enquire whether the serious exploration of the golden section in music should remain largely confined to the domain of classical music. And from this case study of just one aspect/sub-genre of popular music it seems not. Using a time-based rather than score-based methodology as a foundation or jumping-off point, it may be possible to explore a further range of popular music genres in terms of golden section proportionality and any associated impact upon the creative processes involved in the composition of music. To what extent the digital audio workstation-with its visual representational overview of an unfolding composition-might influence these processes is potentially another line of enquiry worthy of future study, which would be particularly relevant to contemporary music composition, given the prevalent use of DAWs in such music.

\section{ACKNOWLEDGMENTS}

We thank Vlado Dzihan for their correspondence during the study. This offered valuable insight into the creative approach of the duo, which was particularly useful when considering the findings of our analysis. 


\section{NOTES}

1 See for example Oldershaw (1982), Green (1995), Zeng and Wang (2009), Chen et al. (2011) and Luttge and Souza (2019).

2 A most recent and unexpected occurrence is to be found in the official press conference video for the Fiat 500, https://www.youtube.com/watch?v=pVBAzeu-HZg (at 9'37”).

3 Zeising's work has been contested by Tatlow in her comprehensive historico-critical overview (see Tatlow 2006: 69-85, where she refers to the practice of "golden numberism" beginning in the 1830s). Tatlow's critique, however, is primarily concerned with matters of compositional intentionality.

4 Lendvai has undertaken extensive analyses of the compositions of Bartók (see Lendvai 1966a; Lendvai 1966b), while Howat's (1983) comprehensive book explores the golden section in the music of Debussy.

5 Examples from the fourteenth and fifteenth centuries include Machaut (Powell 1979), Dunstable (Trowell 1979), Dufay (Sandresky 1981), through Mozart (Perry Camp 1968), to the 20th century with composers such as Satie (Adams 1996), Shostakovitch (Rofe 2016), Stockhausen (Maconie 2005) and Ligeti (Luchese 2001). Jonathan Kramer (1988: 303-4) offers a wider range of composers.

6 With reference to the musique concrète tradition, Lewis (1998) discusses Dhomont's Novars, the structure of which is based on multiple golden sections, while Zattra (2007) undertakes a textual criticism approach in her analysis of John Chowning's electroacoustic work Stria and its associated linkages with the golden section.

7 Exploring possibilities of golden section in instrumental music avoids any potential constraints of popular music song structures which are based on rational numbers (e.g. 4, 8, 16).

8 There is some slight drift in the tempo in some tracks such as Weltempenfanger (2010).

9 Publications that have referenced this overview of EDM form include Snoman (2013), (Solberg 2014), Eigenfeldt and Pasquier (2015) and López-Serrano et al. (2016).

10 We are mainly applying here what Lendvai refers to as the positive (long musical section followed by shorter section at 0.618 ) rather than the negative (short musical section followed by longer section at 0.382 ). We are not applying any complex aspect of the nesting of GS points such as in the analyses by Howat.

11 Taking Adams' concerns into account with respect to Ocean Air, for example, the two thirds/ one third issue would have placed a calculated point of two thirds of the total duration of 5'20" to occur at 3' 33', some distance from the hypothetical GS point of 3'18'.

12 For example, in Waiting (2009, dur 3'27”), this division occurs at 2'01', splitting the song into former (verse-verse-chorus) and latter (verse-chorus) parts that are representative of GS proportionality, 0.618:0.382.

13 The inverse calculated GS point was arrived at by calculating the normal GS point using the previously outlined methodology, but then measuring from the end of the track, as opposed to the start. Essentially, this inverts the order of the larger and smaller GS proportions.

14 To clarify, in EDM form, the breakdown constitutes the longest, most dramatic break from the core, and thus any occurrence of a break section in this present study which did not closely meet the EDM definition or was eclipsed by another more prominent instance in the track, was classified not as a breakdown but as a break. 
15 See also Phillips (2019).

16 The arrange window is the main workspace within a DAW where regions, containing different musical sequences, are repeated, layered and sequenced across a timeline, thereby creating the desired musical arrangement. These regions are visually represented on the screen as blocks of different colours, which the user is able to manipulate using the mouse.

17 Email correspondence with Vlado dZihan, 15th June 2020.

18 Issues of conscious intention are discussed primarily with respect to the work of Debussy and Bartók.

19 Ibid., dZihan (2020).

\section{REFERENCES}

Adams, Courtney. 1996. "Erik Satie and Golden Section Analysis". Music and Letters 77 (2): 242-52. < https://doi.org/10.1093/ml/77.2.242>.

Anderson, Christopher and Arne Eigenfeldt. 2011. "A New Analytical Method for the Musical Study of Electronica”. NYU (New York): The Electroacoustic Music Studies Conference, Sforzando! <https://metacreation.net/gerp/downloads/1_Chris.pdf>, (accessed 15 November 2021).

Atlas, Allan, W. 2003. "Stealing a Kiss at the Golden Section: Pacing and Proportion in the Act 1 Love Duet of La Bohème”. Acta Musicologica 75 (2): 269-91. < http://www.jstor.org/stable/25071221>.

Boykan, Martin. 2004. Silence and Slow Time: Studies in Musical Narrative. Oxford: The Scarecrow Press. <https://www.jstor.org/stable/4487490>.

Butler, Mark. 2006. Unlocking the Groove: Rhythm, Meter, and Musical Design in Electronic Dance Music. Bloomington, IN: Indiana University Press. <https://www.worldcat.org/oclc/156778853>.

Chen, Zhao-Xue, Zhi-Zhen Wang, Ying Sun, Ying Feng-Li Bei. 2011. "Discussion on Microcosmic Derivation of Biological Golden Section Phenomena from DNA Geometric Structure and Snow Flower Generation". Interdisciplinary Sciences: Computational Life Sciences 3(1): 31-5. <https://doi.org/10.1007/s12539-011-0060-2>.

Eigenfeldt, Arne and Philippe Pasquier. 2013. "Evolving Structures for Electronic Dance Music." In Proceedings of the 15th Annual Conference on Genetic and Evolutionary Computation, ed. Christian Blum: 319-26. NYC: Association for Computing Machinery. $<$ https://doi.org/10.1145/2463372.2463415 >.

Green, Christopher. D. 1995. "All that Glitters: A Review of Psychological Research on the Aesthetics of the Golden Section”. Perception 24(8): 937-68. <https://doi.org/10.1068/p240937>.

Howat, Roy. 1993. Debussy in Proportion: A Musical Analysis. Cambridge, UK: Cambridge University Press.

Kramer, Jonathan. 1988. The Time of Music. New York: Schirmer.

Lendvai, Ernest. 1966a. Béla Bartók: An Analysis of his Music. London: Kahn \& Averil.

Lendvai, Ernest. 1966b. "Duality and Synthesis in the Music of Béla Bartók". In Module, Proportion, Symmetry, Rhythm, ed. Georgy Kepes, 173-93. London: Studio Vista.

Lewis, Andrew. 1998. "Francis Dhomont's Novars". Journal of New Music Research 27 (1-2): 67-83. <https://www.tandfonline.com/doi/abs/10.1080/09298219808570739>. 
López-Serrano, Patricio, Christian Dittmar, Jonathan Driedger and Meinard Müller. 2016. "Towards Modeling and Decomposing Loop-Based Electronic Music". In Proceedings of the 17th ISMIR Conference, ed. Michael Mandel, Johanna Devaney, Douglas Turnbull and George Tzanetakis, 502-8. NYC: International Society for Music Information Retrieval. <https://wp.nyu.edu/ismir2016/wp-content/uploads/sites/2294/2016/07/065_Paper.pdf>, (accessed 15 November 2021).

Luchese, Diane. 2001. “Come un Meccanismo di Precisione: The Third Movement of Ligeti’s Second String Quartet". In Bridges: Mathematical Connections in Art, Music and Science; Conference Proceedings 2001, ed. Reza Saranghi and Slavik Jablan, 37-46. Winfield, Kansas: Bridges Conference. <https://archive.bridgesmathart.org/2001/bridges2001-37.pdf>, (accessed 15 November 2021).

Lüttge, Ulrich and Gustavo M. Souza. 2019. "The Golden Section and Beauty in Nature: The Perfection of Symmetry and the Charm of Asymmetry". Progress in Biophysics and Molecular Biology 146: 98-103. <http://dx.doi.org/10.1016/j.pbiomolbio.2018.12.008>.

Macchiusi, Ian. 2017. "Knowing is Seeing: The Digital Audio Workstation and the Visualization of Sound". PhD Dissertation. York University, Toronto. <https://yorkspace.library.yorku.ca/xmlui/handle/10315/34478>.

Maconie, Robin. 2005. Other Planets: The Music of Karlheinz Stockhausen. Lanham, UK: Scarecrow Publishing.

Marrington, Mark. 2010. "Experiencing Musical Composition in the DAW: The Software Interface as Mediator of the Musical Idea". Journal of the Art of Record Production 5. <https:// www.arpjournal.com/asarpwp/experiencing-musical-composition-in-the-daw-the-softwareinterface-as-mediator-of-the-musical-idea-2/>, (accessed 15 November 2021).

Oldershaw, Robert L. 1982. "The Preferred Pitch Angle of Spiral Galaxies: Mathematical and Physical Implications" Monthly Notes of the Astronomical Society of Southern Africa 41: 42-46. $<$ https://ui.adsabs.harvard.edu/abs/1982MNSSA..41...42O >.

Phillips, Michelle. E. 2019. "Rethinking the Role of the Golden Section in Music and Music Scholarship". Creativity Research Journal 31(4): 419-27. <http://dx.doi.org/10.1080/10400419.2019.1651243>.

Powell, Newman W. 1979. "Fibonacci and the Golden mean: Rabbits, Rumbas, and Rondeaux". Journal of Music Theory 23(2): 227-73. <https://www.jstor.org/stable/843726>.

Reybrouck, Mark. 2005. "Body, Mind and Music: Musical Semantics between Experiential Cognition and Cognitive Economy”. Transcultural Music Review 9: 1-54. <https://lirias. kuleuven.be/bitstream/123456789/109134/1//Body,+mind+and+music +musical+semanti cs+between+experiential+cognition+and+cognitive+economy.pdf $>$.

Rofe, Michael. D. 2016. Dimensions of Energy in Shostakovitch. Abingdon, UK: Routledge.

Rofe, Michael D. 2008. "Shostakovitch and the Russian Doll: Dimensions of Energy in the Symphonies”. PhD Dissertation, University of York, UK. <https://etheses.whiterose.ac.uk/11069/>.

Sandresky, Margaret V. 1981. "The Golden Section in Three Byzantine Motets of Dufay”. Journal of Music Theory 25(2): 291-306. <http://dx.doi.org/10.2307/843653>.

Snoman, Rick. 2013. Dance Music Manual. Abingdon, UK: Routledge. <http://dx.doi.org/10.4324/9780203383643>. 
Solberg, Ragnhild. T. 2014. "Waiting for the Bass to Drop: Correlations between Intense Emotional Experiences and Production Techniques in Build-up and Drop Sections of Electronic Dance Music". Dancecult 6(1): 61-82. <http://dx.doi.org/10.12801/1947-5403.2014.06.01.04 >.

Solberg, Ragnhild. T. and Alexander Jensenius. 2017. "Pleasurable and Intersubjectively Embodied Experiences of Electronic Dance Music”. Empirical Musicology Review 11(3-4): 301-18. <http://dx.doi.org/10.18061/emr.v11i3-4.5023 >.

Tatlow, Ruth. 2006. "The Use and Abuse of Fibonacci Numbers and the Golden Section in Musicology Today”. Understanding Bach 1: 69-85. <https://www.bachnetwork.org/ub1/tatlow.pdf>, (accessed 15 November 2021).

Trowell, Brian. 1979. "Proportions in the Music of Dunstable". Proceedings of the Royal Musical Association 195: 100-41. <http://dx.doi.org/10.1093/jrma/105.1.100>.

Verba, Emily. 2012. "The Golden Ratio in Time-Based Media”. Journal of Arts and Humanities 1(1): 56-68. <https://www.theartsjournal.org/index.php/site/article/download/6/6>, (accessed 15 November 2021).

Zattra, Laura. 2007. “The Assembling of Stria by John Chowning: A Philological Investigation”. Computer Music Journal 31(3): 38-64. <https://www.jstor.org/stable/40072593 >.

Zeising, Adolf. 1854. Neue Lehre van den Proportionen des meschlischen Körpers. Leipzig: Rudolph Weigel.

Zeising, Adolf. 1855. Aesthetic Research. Frankfurt a.M: Verlag von Heidinger John and Company.

Zeng, Lanling, Guozhao Wang. 2009. “Modeling Golden section in Plants”. Progress in Natural Science 19(2): 255-60. <http://dx.doi.org/10.1016/j.pnsc.2008.07.004 >.

DISCOGRAPHY

dZihan \& Kamien. 1999. Tearoom 2004. Couch Records (CD): CR 21007. <https://www.discogs.com/master/128589-dZihan-Kamien-Tearoom-2004>.

——_. Freaks \& Icons. 2000. Couch Records (CD): 657036 1036-2. <https://www.discogs.com/master/128591-dZihan-Kamien-Freaks-Icons >.

-_-. Smile. 2001. Couch Records (CD): 657036 5044-2. <https://www.discogs.com/master/128596-dZihan-Kamien-Smile>.

-_- Sliding. 2002. Couch Records (CD): CR 20162. <https://www.discogs.com/master/128595-dZihan-Kamien-Sliding>.

-_- Gran Riserva. 2002. Couch Records (CD): 657036 1080-2. $<$ https://www.discogs.com/master/128592-dZihan-Kamien-Gran-Riserva $>$.

_-_. Music Matters. 2009. Couch Records (CD): CR 20582. <https://www.discogs.com/master/1818827-dZihan-Kamien-Music-Matters $>$.

-_- Lost And Found. 2010. Couch Records (CD): CR 20662. <https://www.discogs.com/master/1093792-dZihan-Kamien-Lost-And-Found >.

- - I've Seen. 2018. Couch Records (CD): Couch Records. <https://www.discogs.com/release/18356509-dZihan-Kamien-IV>.

- - . 99. 2020. Couch Records (CD): Couch Records. <https://www.discogs.com/release/18356509-dZihan-Kamien-IV>. 